\title{
Gold-Catalyzed Post-Polymerization Modification of Commodity Aromatic Polymers
}

\author{
Eric R. King, Samuel B. Hunt, Levi J. Hamernik, Lauren E. Gonce, Jeffrey S. Wiggins, \\ and Jason D. Azoulay*
}

Cite This: JACS Au 2021, 1, 1342-1347

Read Online

\section{ACCESS $\mid$}

W Metrics \& More

Article Recommendations

Supporting Information

ABSTRACT: Synthetic aromatic polymers are ubiquitous and indispensable to modern life, industry, and the global economy. The direct functionalization of these materials remains a considerable challenge on account of their unreactive aromatic $\mathrm{C}-\mathrm{H}$ bonds and robust physical properties. Here, we demonstrate that homogeneous gold catalysis offers a mild, chemoselective, and practical approach to functionalize high-volume commodity aromatic polymers. Utilizing a gold-catalyzed intermolecular hydroarylation between a methyl ester functionalized alkyne, methyl propiolate, and nucleophilic arenes within polystyrene (PS) results in direct functionalization of phenyl rings with 1,2-substituted methyl acrylate functional groups. The reactivity and

High Volume Commodity Aromatic Polymers functionalization depend on the steric and electronic environment of the catalyst, counterion pairing, and method of activation. The reactivity is broad in scope, enabling the functionalization of arenes within commercial polysulfone (PSU) and waste polyethylene terephthalate (PET). These reactions open new opportunities to chemically transform aromatic polymers and modify their physical properties.

KEYWORDS: Polymers, Catalysis, Functionalization, Gold, Aromatic Compounds

\begin{abstract}
A romatic polymers-those that contain planar, rigid aromatic, or pseudoaromatic heterocycles-display robust chemical, mechanical, and thermal properties. This enables their broad utility in commodity, specialty, and highperformance applications such as packaging, textiles, transportation, electronics, construction, healthcare, energy, and many others. ${ }^{1-3}$ Polystyrene (PS) and polyethylene terephthalate (PET) are two of the most widely utilized aromatic polymers with an annual global production exceeding 25 and 33 million metric tons, respectively (Figure 1a). ${ }^{4}$ Fully aromatic engineering thermoplastics such as polysulfone (PSU, Figure 1a) find use in high-performance applications. ${ }^{1}$ The direct modification of high-volume aromatic polymers would have far-reaching implications toward expanding their utility and enabling new functionality. ${ }^{1,5-7}$ However, the chemical stability and physical properties that make these plastics valuable also make their chemical conversion to new products a grand challenge. ${ }^{8}$

The most widely applied methods for the post-polymerization modification (PPM) of aromatic units within these polymers are Friedel-Crafts alkylations and acylations (Figure 1b). ${ }^{5,8,9}$ Other reactions have been applied such as halomethylation, perfluoroalkylation, alkyl-Li metalation, potassium superbase metalation, sulfonation, and Ir-catalyzed borylation (Figure 1b). ${ }^{5,8,10,11}$ These approaches enable the synthesis of reactive polymer precursors and the installation of functionality that dramatically improves adhesion, chemical
\end{abstract}

compatibility, mechanical properties, viscoelasticity, processability, and so on. ${ }^{5,9,12}$ This also enables the creation of valueadded materials such as blend compatibilizers, flame retardants, ion-exchange resins, and catalyst supports. ${ }^{10,12-14}$ However, these chemistries are generally nonselective, necessitate multiple steps, require harsh conditions that result in deleterious side reactions, and yield products that require cumbersome purification. ${ }^{2,5,8}$ Thus, PPM strategies have largely relied on the utilization of functionalized monomers that do not interfere with the polymerization process and offer orthogonal and high yielding ("click-like") reactivity when embedded within the polymer." ${ }^{6,15}$ While the literature is replete with examples of such approaches, this strategy is largely incompatible with the centralized, high-volume syntheses of polymers that rely on commodity monomer feedstocks and established production processes that cannot accommodate specialty monomers. ${ }^{16}$

Consequently, there remains a need to develop practical and chemoselective approaches for the direct functionalization of these commodity materials. We recently demonstrated the first

Received: May 12, 2021

Published: July 21, 2021 
A) Commercial Aromatic Polymers<smiles>CC(C(C)(C)C)C(C)(C)C</smiles>

Polystyrene (PS)

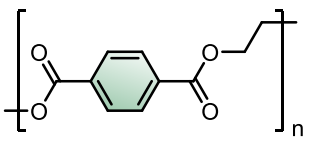

Polyethylene Terephthalate (PET)

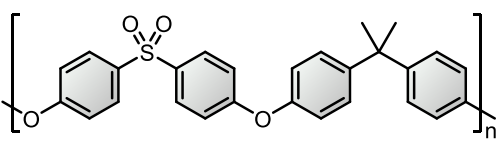

Polysulfone (PSU)

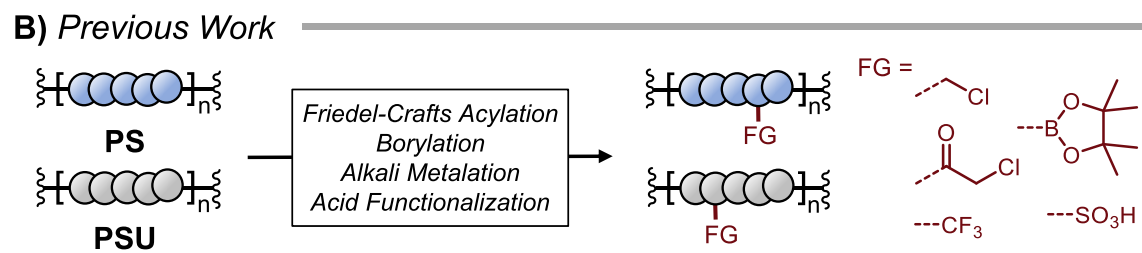

PSU

$---\mathrm{CF}_{3}$

- Harsh Reaction Conditions • Side Reactions • Poor Selectivity • Low Yields

C) Gold Catalyzed Functionalization

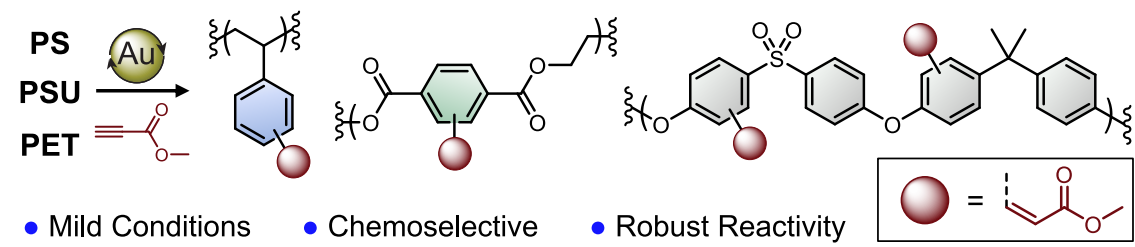

Figure 1. a) Commercial aromatic polymers and (b) common strategies for the post-polymerization modification of PS and PSU. (c) Au-catalyzed hydroarylation applied to $\mathrm{C}\left(\mathrm{sp}^{2}\right)-\mathrm{H}$ aromatic bonds resulting in installation of methyl acrylate functional groups.

catalytic application of homogeneous gold $(\mathrm{Au})$ complexes toward the $\mathrm{C}-\mathrm{H}$ functionalization polycondensation of alkynecontaining comonomers and aromatic nucleophiles resulting in high molecular weight aromatic copolymers. ${ }^{17}$ We investigated whether this intermolecular reactivity in hydroarylations ${ }^{18,19}$ could be applied to the challenging PPM of aromatic polymers as highlighted in Figure 1c.

Styrenic polymers and copolymers constitute a broad family of materials whose applications remain restricted by the absence of polar functionality. ${ }^{3,5}$ Acrylates are ubiquitous in polymers and their incorporation within nonpolar plastics using catalytic approaches provides a range of useful physical properties. ${ }^{5,20-22}$ As summarized in Table 1, we evaluated the reaction between PS and methyl propiolate (1) toward methyl acrylate functionalized PS. We utilized PS with a numberaverage molecular weight $\left(M_{\mathrm{n}}\right)$ of $13,135 \mathrm{~g} \mathrm{~mol}^{-1}$ and narrow dispersity $(\nexists=1.03)$ to establish clear correlations between catalyst structure, degree of functionalization, and to monitor side reactions. Commercially available catalysts $\left[\mathrm{L}_{n} \mathrm{AuX}\right]$ comprising variations in ligand $\left(\mathrm{L}_{n}\right)$ sterics, electronics, and nature of the counterion $\left(\mathrm{Y}^{-}\right)$were initially evaluated in 1,2dichloroethane $\left(\mathrm{C}_{2} \mathrm{H}_{4} \mathrm{Cl}_{2}\right)$, dichloromethane $\left(\mathrm{CH}_{2} \mathrm{Cl}_{2}\right)$, and chloroform $\left(\mathrm{CHCl}_{3}\right)$ at reaction temperatures $\left(T_{\text {rxn }}\right)$ ranging from 25 to $80{ }^{\circ} \mathrm{C}$. Modulation of ion pairing as a function of solvent dielectric $(\varepsilon)$ demonstrated a profound effect on reactivity. ${ }^{17,23,24}$ Reactions utilizing 2 equiv of 1 per repeat unit of PS (i.e., $[1] /[\mathrm{PS}]=2$ ) showed high reactivities but resulted in branching through a double hydroarylation (Table S3). ${ }^{25}$ Increasing $[1] /[\mathrm{PS}]$ to 10 equiv suppressed the double hydroarylation pathway and enabled the controlled functionalization of PS. Full details of initial studies are provided in Tables S1-S3 (Supporting Information). As summarized in Table 1, PS concentrations of $0.85 \mathrm{M},[1] /[\mathrm{PS}]=10, T_{\mathrm{rxn}}=25$ ${ }^{\circ} \mathrm{C}, 2 \mathrm{~mol} \%$ catalyst, and $\mathrm{C}_{2} \mathrm{H}_{4} \mathrm{Cl}_{2}$ (highest $\varepsilon$ ) favored suitable activities and reasonable degrees of functionalization (i.e.,
Table 1. Evaluation of Catalysts for the PPM of PS ${ }^{a}$

Catalyst
1

${ }^{a}$ Conditions: PS $(0.48 \mathrm{mmol}), 1(4.80 \mathrm{mmol})$, Au catalyst $(2 \mathrm{~mol} \%)$, $\mathrm{AgSbF}_{6}(6 \mathrm{~mol} \%), \mathrm{C}_{2} \mathrm{H}_{4} \mathrm{Cl}_{2}, 25{ }^{\circ} \mathrm{C}$. ${ }^{b}$ Determined by gel permeation chromatography (GPC) at $45{ }^{\circ} \mathrm{C}$ in tetrahydrofuran. ${ }^{c}$ Determined from ${ }^{1} \mathrm{H}$ NMR analysis; see equation S2 (Supporting Information).

percentage of repeat units functionalized), enabling comparative studies between catalysts. 

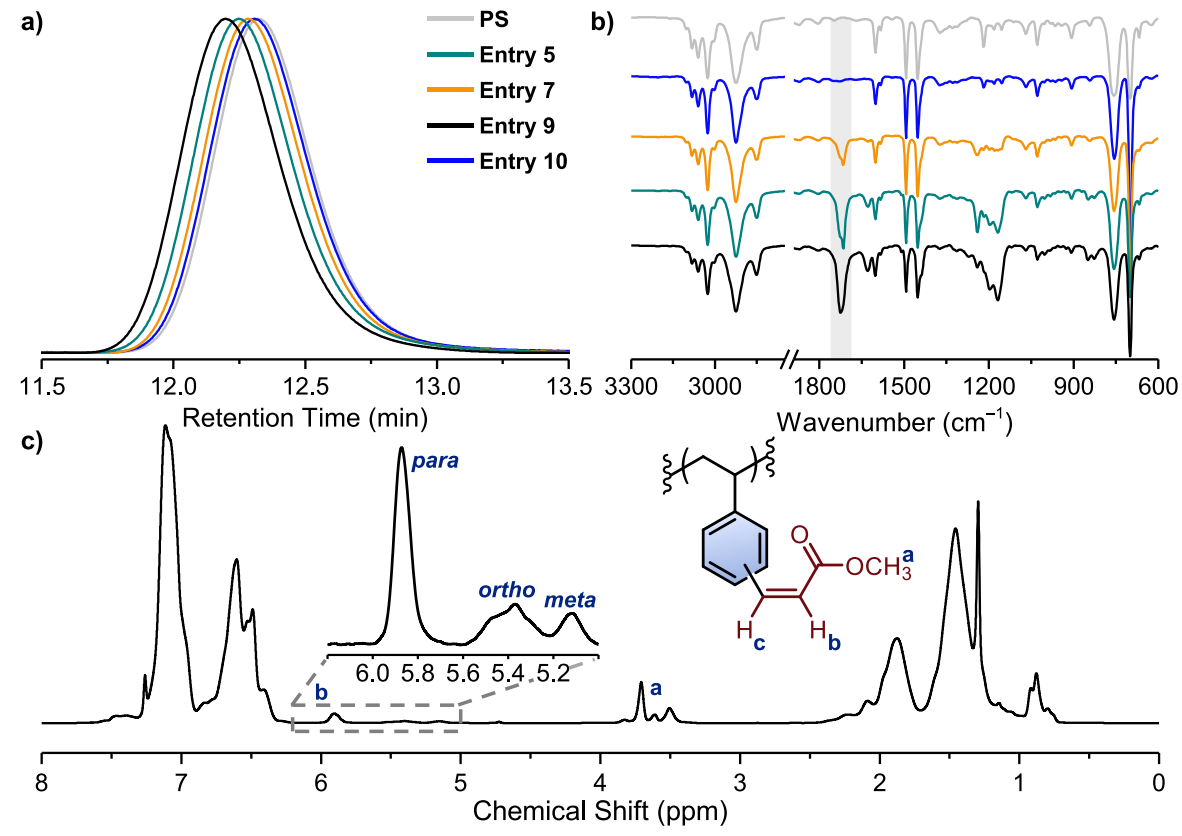

Figure 2. (a) GPC traces and (b) FT-IR spectra of PS and entries 5, 7, 9, and 10 of Table 1. (c) ${ }^{1} \mathrm{H}$ NMR spectrum of functionalized PS (Table 1, entry 9) highlighting methyl ester $\left(\mathrm{H}_{\mathrm{a}}\right)$ and 1,2-disubstituted alkene $\left(\mathrm{H}_{\mathrm{b}}\right.$ and $\left.\mathrm{H}_{\mathrm{c}}\right)$ resonances of the functionalized repeat units within the polymer.

We first explored potent $\mathrm{Au}(\mathrm{I})$ hydroarylation catalysts based on the dialkylbiaryl phosphine ligands 2-dicyclohexylphosphino-2',6-dimethoxybiphenyl (Sphos, A) and 2-(ditert-butylphosphino)biphenyl (JohnPhos, B and C) with a bis(trifluoromethylsulfonyl)imidate counterion $\left[\mathrm{L}_{n} \mathrm{Au}^{+} \mathrm{NTf}_{2}{ }^{-}\right]$ (A) or a coordinating nitrile (NCMe) ligand with an $\mathrm{SbF}_{6}{ }^{-}$ counterion $\left[\mathrm{L}_{n} \mathrm{Au}(\mathrm{NCMe})^{+}\right]\left[\mathrm{SbF}_{6}^{-}\right](\mathbf{B}) .^{26,27}$ The direct use of $\mathbf{A}$ and $\mathbf{B}$ resulted in low levels of functionalization of $\leq 0.9 \%$ (Table 1, entries 2-3) suggesting that relatively coordinating $\mathrm{NTf}_{2}^{-}$counterions or NCMe ligands limit reactivity. This prompted our investigation of $\mathrm{Au}$ chloride complexes $\left[\mathrm{L}_{n} \mathrm{AuCl}\right]$, which upon activation with $\mathrm{AgSbF}_{6}$ provide highly active catalysts with more weakly coordinating $\mathrm{SbF}_{6}{ }^{-}$counterions $\left[\mathrm{L}_{n} \mathrm{Au}^{+} \mathrm{SbF}_{6}{ }^{-}\right]^{28,29}$ Activation of $\mathbf{C}$ with $\mathrm{AgSbF}_{6}$ resulted in an increase in functionalization to $3.3 \%$ (entry 4 ).

The low levels of functionalization prompted our investigation of different ligand architectures. A series of $\left[\mathrm{L}_{n} \mathrm{AuCl}\right]$ complexes were explored, including tris(2,4-di-tertbutylphenyl)phosphite $\left(\mathrm{P}\left[\mathrm{OPh}(t \mathrm{Bu})_{2}\right]_{3}, \mathrm{D}\right)$, tri-tert-butylphosphine $\left(\mathrm{P}(t \mathrm{Bu})_{3}, \mathrm{E}\right)$, and several triaryl $(\mathrm{Ar})$ phosphines, where $\mathrm{Ar}=\mathrm{C}_{6} \mathrm{~F}_{5}(\mathbf{F}), \mathrm{Ar}=$ ortho-tolyl (o-tolyl, $\left.\mathbf{G}\right)$, and $\mathrm{Ar}=\mathrm{C}_{6} \mathrm{H}_{5}$ $\left(\mathrm{PPh}_{3}, \mathbf{H}\right)$. The electrophilic $\mathbf{D} / \mathrm{AgSbF}_{6}$ combination led to an increase in functionalization to $11.1 \%$ (entry 5), ${ }^{26,30}$ slightly higher than $\mathrm{E} / \mathrm{AgSbF}_{6}$ (8.4\%, entry 6). Next, we evaluated triaryl phosphines which enable a direct comparison of steric and electronic effects. While $\mathrm{F} / \mathrm{AgSbF}_{6}$ resulted in $2.5 \%$ functionalization (entry 7 ), the utilization of $\mathbf{G} / \mathrm{AgSbF}_{6}$ with sterically bulky $o$-tolyl ligands resulted in $11.8 \%$ (entry 8 ). ${ }^{31}$ Of the initiators and catalysts screened, $\mathrm{H} / \mathrm{AgSbF}_{6}$ resulted in the highest functionalization of $17.4 \%$ (entry 9 ), consistent with an increase in $M_{\mathrm{n}}$ to $14,568 \mathrm{~g} \mathrm{~mol}^{-1}$. N-Heterocyclic carbene (NHC) complexes with 1,3-bis(2,6-diisopropylphenyl)imidazol-2-ylidene (IPr) ligands were examined on account of their high reactivities. ${ }^{17,32,33}$ Consistent with the low reactivity obtained using $\mathbf{B}$, the direct use of $\mathbf{I}$ resulted in $0.8 \%$ functionalization (entry 10 ), while activation of $\mathbf{J}$ with $\mathrm{AgSbF}_{6}$ resulted in $11.6 \%$ (entry 11).
Since important polymer properties (e.g., adhesion, toughness, surface properties, chemical compatibility, reactivity, processability, etc.) are dramatically affected by the presence of even small amounts functionality $(>1 \%),{ }^{8,34}$ we systematically lowered the catalyst loading using the conditions in entry 9. The $\mathbf{H} / \mathrm{AgSbF}_{6}$ combination showed functionalization of 2.74 , 0.78 , and $0.41 \%$ at loadings of 2000, 500, and $200 \mathrm{ppm}$, respectively (Figure S3). Moreover, we demonstrate the methyl acrylate functionality provides a robust handle for subsequent PPM. For example, thiol-ene "click" approaches applied to functionalized PS enabled the rapid and quantitative installation of a fluorinated thiol $(1 \mathrm{H}, 1 \mathrm{H}, 2 \mathrm{H}, 2 \mathrm{H}$-perfluorodecanethiol) to the alkene or cross-linking in the presence of a bifunctional thiol (Section S8, Supporting Information).

The polymer products were further characterized using infrared (FT-IR, Figure 2b) and NMR spectroscopies. FT-IR spectra of entries $5,7,9$, and 10 from Table 1 confirmed the presence of a prominent carbonyl stretch at $1725 \mathrm{~cm}^{-1}$ (Figure 2b). ${ }^{1} \mathrm{H}$ NMR spectra revealed broad overlapping peaks from 3.9-3.3 ppm for methyl ester protons $\left(\mathrm{H}_{\mathrm{a}}\right)$ (Figure $2 \mathrm{c}$ ). These signatures arise from the atactic structure of the PS and functionalization at ortho, meta, and predominately para positions of the phenyl groups. This regiochemical distribution is also apparent from three distinct alkene signals at 5.9 (para), 5.4 (ortho), and $5.2 \mathrm{ppm}$ (meta). ${ }^{1} \mathrm{H}-{ }^{13} \mathrm{C}$ HSQC experiments unambiguously confirm this assignment (Figure S35). For entry 9, as evident from the peak integrations (Table S4 and Figure S32), the para-substituted isomer is dominant ( $62 \%)$, while ortho- and meta-substitution accounts for $\sim 23 \%$ and $\sim 15 \%$, respectively. This distribution is expected on account of steric and electronic preferences in Au-catalyzed hydroarylations and accessibility of sites within the polymer. The $\beta$-carbonyl alkene proton $\left(\mathrm{H}_{c}\right)$ is occluded by the aromatic protons on account of its highly deshielded nature; thus, ${ }^{1} \mathrm{H}-{ }^{1} \mathrm{H}$ COSY experiments were utilized to reveal alkene correlations at 6.8 and $5.9 \mathrm{ppm}$ (Figure S34). This correlation corroborates the vicinal regiochemistry of the alkene, which 
a)



Entry Catalyst [1]/[PSU] Functionality

\begin{tabular}{cccc}
1 & G & 10 & $12.2 \%$ \\
2 & H & 10 & $5.9 \%$ \\
3 & J & 10 & $4.1 \%$ \\
4 & G & 2 & $20.2 \%$ \\
5 & H & 2 & $21.6 \%$ \\
6 & $\mathbf{J}$ & 2 & $18.2 \%$ \\
\hline
\end{tabular}

c)

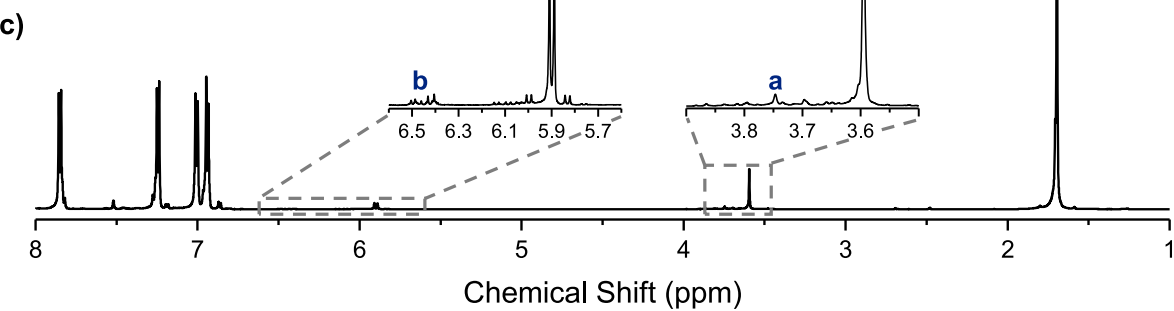

b) PSU
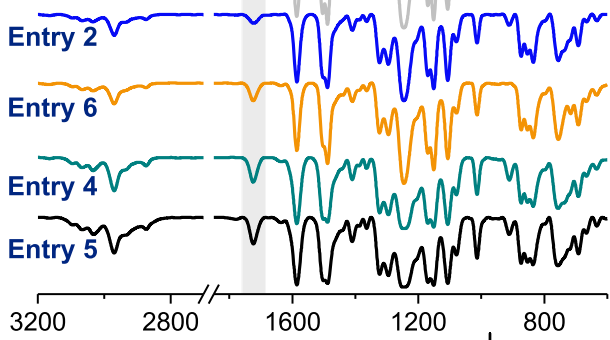

Wavenumber $\left(\mathrm{cm}^{-1}\right)$

800


Figure 3. (a) PPM of PSU with 1 highlighting a functionalized fragment; see Supporting Information for full details. The functionalization was calculated using ${ }^{1} \mathrm{H}$ NMR. (b) Overlay of FT-IR spectra of PSU and entries 2, 4, 5, and 6. (c) ${ }^{1} \mathrm{H}$ NMR spectrum in $\mathrm{CDCl}_{3}$ of functionalized PSU, entry 5 .

adopts a Z-conformation on account of anti-Markovnikov attack of the $\eta^{2}$-[Au $\left.{ }^{+}\right]$-activated alkyne intermediate in the hydroarylation reaction. ${ }^{18,19,26}$ The correlations between GPC, FT-IR, and NMR data are consistent with the high chemoselectivity of the process.

Functionalized PS (14.8\%) demonstrates markedly different thermal, physical, and viscoelastic properties. Differential scanning calorimetry (DSC) is consistent with a depression in the glass transition temperature $\left(T_{\mathrm{g}}\right)$ from $97.7^{\circ} \mathrm{C}$ in the unmodified polymer to $93.0{ }^{\circ} \mathrm{C}$ (Figure S12). Comparative dynamic mechanical analysis (DMA) studies revealed that the modulus of the glassy functionalized polymer increased by $\sim 13 \%$ along with an increase in melt viscosity above $160{ }^{\circ} \mathrm{C}$ (Figures S15-S16). Thermogravimetric analysis (TGA) suggests that thermal decomposition of the functionalized PS begins at $\sim 382{ }^{\circ} \mathrm{C}$, only $14.6{ }^{\circ} \mathrm{C}$ lower than the unfunctionalized PS and consistent with high stability (Figures S20-S21). The contact angle $(\theta)$ of the functionalized PS $\left(90.7^{\circ}\right)$ was smaller than the unmodified PS $\left(95.4^{\circ}\right)$, indicative of an increase in the nondispersive (polar) component of the surface free energy and greater wettability for water (Table S7 and Figure S24). ${ }^{35}$

Having established appropriate reaction conditions that facilitate robust functionalization, we investigated polymer substrate scope. We first targeted PSU, a prototypical engineering thermoplastic with contrasting material properties to PS. These include aromatic units within the polymer backbone with distinct linkages, a rigid-rod structure, and high intrinsic viscosity $[\eta]$, which required lowering PSU concentrations to $0.50 \mathrm{M}$. As summarized in Figure $3 \mathrm{a}$, the use of $[\mathbf{1}] /$ $[\mathrm{PSU}]=10, \mathrm{~T}_{\mathrm{rxn}}=25^{\circ} \mathrm{C}, \mathrm{C}_{2} \mathrm{H}_{4} \mathrm{Cl}_{2}$, and catalysts $\mathbf{G}, \mathbf{H}$, and $\mathbf{J}$ activated with $\mathrm{AgSbF}_{6}$, resulted in degrees of functionalization of $12.2,5.9$, and $4.1 \%$ respectively (Figure 3a, entries 1-3). Reducing the $[1] /[\mathrm{PSU}]$ ratio from 10 to 2 equiv resulted in an increase in functionalization to $20.2,21.6$, and $18.2 \%$ (entries 4-6). No signatures of the double hydroarylation product were evident.

FT-IR spectra of entries 1-6 in Figure 3a reveal a carbonyl stretch at $1725 \mathrm{~cm}^{-1}$ that shows a concomitant increase in intensity with functionalization (Figure $3 \mathrm{~b}$ ). This is in agreement with an increase in $M_{\mathrm{n}}$ from 23,731 (PSU) to $27,282 \mathrm{~g} \mathrm{~mol}^{-1}$ (21.6\%, entry 4) (Figure S6). ${ }^{1} \mathrm{H}$ NMR spectra (Figure 3c) are consistent with the presence of methyl ester $\left(\mathrm{H}_{\mathrm{a}}\right.$ and $\left.\mathrm{H}_{\mathrm{d}}\right)$ and $\alpha$-carbonyl protons $\left(\mathrm{H}_{\mathrm{b}}\right.$ and $\left.\mathrm{H}_{\mathrm{e}}\right)$. These resonances appear as two distinct peaks resulting from substitution within different arenes in the PSU backbone (Figure 3a,c). 9,11,36 The $\mathrm{H}_{\mathrm{a}}$ and $\mathrm{H}_{\mathrm{b}}$ resonances appear further downfield at 3.8 and 6.4 ppm relative to $H_{d}$ and $H_{e}$ at 3.6 and $5.9 \mathrm{ppm}$ on account of their proximity to the electronwithdrawing sulfonyl linker. These electronic features promote functionalization predominately ortho to the bridging ether linkage (Figure 3a). The $\beta$-carbonyl alkene protons $\left(\mathrm{H}_{\mathrm{c}}\right.$ and $\mathrm{H}_{\mathrm{f}}$ ) are occluded by the aromatic proton signals; however, ${ }^{1} \mathrm{H}-{ }^{1} \mathrm{H}$ COSY and ${ }^{1} \mathrm{H}-{ }^{13} \mathrm{C}$ HSQC experiments corroborate these assignments (Figures S39-S40). Functionalized PSU (9.7\%) demonstrates a modest depression in the $T_{\mathrm{g}}$ from 181.4 ${ }^{\circ} \mathrm{C}$ in the unmodified polymer to $174.3{ }^{\circ} \mathrm{C}$ (Figure S13) and a $5.4{ }^{\circ} \mathrm{C}$ decrease in decomposition temperature (Figures S22S23). DMA revealed a monotonic decrease in the modulus $(\sim 21.9 \%$, Figure S18) and complex viscosity ( 23.0\%, Figure S19) when compared to the unfunctionalized PSU. The decrease in $T_{\mathrm{g}}$ and thermomechanical behavior can be attributed to increased flexibility of the rigid rod PSU. These results illustrate significant enhancements in melt processability while minimally affecting $T_{\mathrm{g}}$ and thermal stability, highly sought-after attributes for engineering thermoplastics.

PET, a broadly utilized semicrystalline aromatic thermoplastic is intractable in most organic solvents. This necessitates the use of strong acids to promote solubility, which precludes the use of most PPM approaches, organic reagents, and 
catalytic species. PET sourced directly from a discarded soda bottle was dissolved in a 1:2 mixture of trifluoroacetic acid (TFA) and $\mathrm{C}_{2} \mathrm{H}_{4} \mathrm{Cl}_{2}$. The PPM reaction proceeded using optimal reaction conditions (Table 1, entry 9) under ambient conditions by injecting a solution of preactivated catalyst into the reaction mixture. This resulted in PET with $1.4 \%$ functionalization (Figure 4a, entry 3), while utilization of $\mathbf{C}$ /
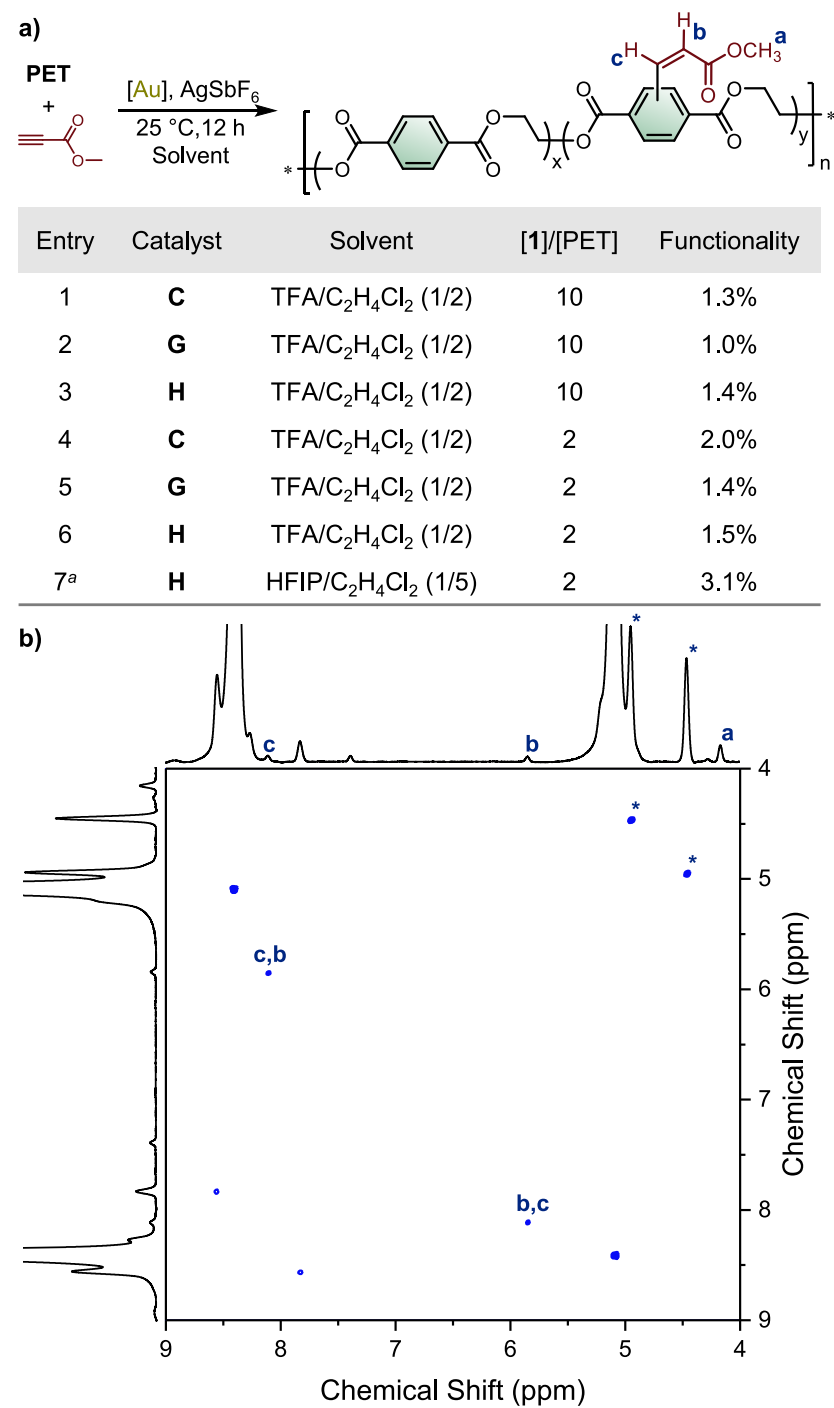

Figure 4. (a) PPM of PET using 1. The functionalization was calculated using ${ }^{1} \mathrm{H}$ NMR. (b) ${ }^{1} \mathrm{H}-{ }^{1} \mathrm{H}$ COSY spectrum in $\mathrm{CF}_{3} \mathrm{COOD}$ of methacrylate functionalized PET, entry $4 .{ }^{a}$ PET concentration was $0.30 \mathrm{M}$.

$\mathrm{AgSbF}_{6}$ resulted in $2.0 \%$ functionalization (entry 4). This could be further improved to $3.1 \%$ through substitution of TFA for hexafluoro-2-propanol (HFIP) despite the lower solubility of PET in HFIP and reduced concentration of 0.30 $\mathrm{M}$ (entry 7$).{ }^{1} \mathrm{H}$ NMR spectra in TFA-d ( $\left.\mathrm{CF}_{3} \mathrm{COOD}\right)$ depict a broad methyl ester resonance $\left(\mathrm{H}_{\mathrm{a}}\right)$ (Figure $4 \mathrm{~b}$ and Figure $\mathrm{S} 43$ ) and the corresponding $\alpha$-carbonyl proton $\left(\mathrm{H}_{\mathrm{b}}\right)$ and $\beta$-carbonyl alkene proton $\left(\mathrm{H}_{\mathrm{c}}\right)$ at 6.7 and $8.0 \mathrm{ppm}$, respectively. ${ }^{1} \mathrm{H}-{ }^{1} \mathrm{H}$ COSY spectra validates the vicinal regiochemistry of the alkene, revealing correlations between $\mathrm{H}_{b}$ and $\mathrm{H}_{c}$ (Figure $4 \mathrm{~b}$ ).

In summary, we report the first example of the PPM of highvolume commodity aromatic polymers using homogeneous $\mathrm{Au}$ catalysis. Utilizing a prototypical Au-catalyzed intermolecular hydroarylation between methyl propiolate and nucleophilic arenes within PS, PSU, and PET results in their direct functionalization with methyl acrylate functional groups. The reactions are chemoselective, and they proceed using mild conditions and in the absence of side reactions. The dramatic differences in product distributions demonstrate that catalyst structure plays a pivotal role in determining the efficacy of PPM reactions. The functionalized products exhibited significant changes to important physical properties such as $T_{\mathrm{g}}$, modulus, melt viscosity, and wettability. In contrast to other PPM chemistries, the novel attributes of Au catalysts enable the direct functionalization of waste PET. These initial demonstrations provide a platform to extend the novel reactivity of $\mathrm{Au}$ toward the PPM of aromatic polymers.

\section{ASSOCIATED CONTENT \\ Supporting Information}

The Supporting Information is available free of charge at https://pubs.acs.org/doi/10.1021/jacsau.1c00208.

Experimental procedures and characterization data for all compounds (PDF)

\section{AUTHOR INFORMATION}

\section{Corresponding Author}

Jason D. Azoulay - School of Polymer Science and Engineering, The University of Southern Mississippi, Hattiesburg, Mississippi 39406, United States; 10 orcid.org/ 0000-0003-0138-5961; Email: jason.azoulay@usm.edu

\section{Authors}

Eric R. King - School of Polymer Science and Engineering, The University of Southern Mississippi, Hattiesburg, Mississippi 39406, United States

Samuel B. Hunt - School of Polymer Science and Engineering, The University of Southern Mississippi, Hattiesburg, Mississippi 39406, United States

Levi J. Hamernik - School of Polymer Science and Engineering, The University of Southern Mississippi, Hattiesburg, Mississippi 39406, United States

Lauren E. Gonce - School of Polymer Science and Engineering, The University of Southern Mississippi, Hattiesburg, Mississippi 39406, United States

Jeffrey S. Wiggins - School of Polymer Science and Engineering, The University of Southern Mississippi, Hattiesburg, Mississippi 39406, United States; 10 orcid.org/ 0000-0001-7662-0669

Complete contact information is available at: https://pubs.acs.org/10.1021/jacsau.1c00208

\section{Author Contributions}

E.R.K., S.B.H., and L.E.G. carried out the synthesis and characterization of the polymers. L.J.H. conducted thermomechanical and physical property characterization under the supervision of J.S.W. E.R.K., S.B.H., and J.D.A. wrote the manuscript. J.D.A. oversaw the study.

Notes

The authors declare the following competing financial interest(s): E.R.K., S.B.H., and J.D.A. are inventors on a patent application filed by the University of Southern Mississippi for the reactions described in this Communication. 


\section{ACKNOWLEDGMENTS}

This material is based upon work supported by the U.S. Department of Energy, Office of Science, Office of Basic Energy Sciences, under Award Number DE-SC0021161

\section{REFERENCES}

(1) Fink, J. K. High Performance Polymers, 2nd ed.; William Andrew Publishing, 2014.

(2) Shukla, D.; Negi, Y. S.; Sen Uppadhyaya, J.; Kumar, V. Synthesis and Modification of Poly(Ether Ether Ketone) and their Properties: A Review. Polym. Rev. 2012, 52, 189-228.

(3) Maul, J.; Frushour, B. G.; Kontoff, J. R.; Eichenauer, H.; Ott, K.H.; Schade, C. Polystyrene and Styrene Copolymers. Ullmann's Encyclopedia of Industrial Chemistry; Wiley-VCH, 2007, 475-522.

(4) Geyer, R.; Jambeck, J. R.; Law, K. L. Production, Use, and Fate of All Plastics Ever Made. Sci. Adv. 2017, 3, e1700782.

(5) Zinck, P.; Bonnet, F.; Mortreux, A.; Visseaux, M. Functionalization of Syndiotactic Polystyrene. Prog. Polym. Sci. 2009, 34, 369-392.

(6) Blasco, E.; Sims, M. B.; Goldmann, A. S.; Sumerlin, B. S.; BarnerKowollik, C. 50th Anniversary Perspective: Polymer Functionalization. Macromolecules 2017, 50, 5215-5252.

(7) Fagnani, D. E.; Tami, J. L.; Copley, G.; Clemons, M. N.; Getzler, Y. D. Y. L.; McNeil, A. J. 100th Anniversary of Macromolecular Science Viewpoint: Redefining Sustainable Polymers. ACS Macro Lett. 2021, 10, 41-53.

(8) Williamson, J. B.; Lewis, S. E.; Johnson, R. R., 3rd; Manning, I. M.; Leibfarth, F. A. C-H Functionalization of Commodity Polymers. Angew. Chem., Int. Ed. 2019, 58, 8654-8668.

(9) Abatti, G. P.; Gross, I. P.; da Conceição, T. F. Tuning the Thermal and Mechanical Properties of PSU by Post-Polymerization Friedel-Crafts Acylation. Eur. Polym. J. 2021, 142, 110111.

(10) Dizman, C.; Tasdelen, M. A.; Yagci, Y. Recent Advances in the Preparation of Functionalized Polysulfones. Polym. Int. 2013, 62, 991-1007.

(11) Jo, T. S.; Kim, S. H.; Shin, J.; Bae, C. Highly Efficient Incorporation of Functional Groups into Aromatic Main-Chain Polymer Using Iridium-Catalyzed $\mathrm{C}-\mathrm{H}$ Activation and SuzukiMiyaura Reaction. J. Am. Chem. Soc. 2009, 131, 1656-7.

(12) Moulay, S. Functionalized Polystyrene and PolystyreneContaining Material Platforms for Various Applications. Polym.Plast. Technol. Eng. 2018, 57, 1045-1092.

(13) Iulianelli, A.; Basile, A. Sulfonated PEEK-Based Polymers in PEMFC and DMFC Applications: A Review. Int. J. Hydrogen Energy 2012, 37, 15241-15255.

(14) Zhao, C.; Xue, J.; Ran, F.; Sun, S. Modification of Polyethersulfone Membranes - A Review of Methods. Prog. Mater. Sci. 2013, 58, 76-150.

(15) Gauthier, M. A.; Gibson, M. I.; Klok, H. A. Synthesis of Functional Polymers by Post-Polymerization Modification. Angew. Chem., Int. Ed. 2009, 48, 48-58.

(16) Voit, B. New Polymers: Beautiful Structures, But How Can We Bring Them to the Market? Angew. Chem., Int. Ed. 2017, 56, 28102811.

(17) King, E. R.; Tropp, J.; Eedugurala, N.; Gonce, L. E.; Stanciu, S.; Azoulay, J. D. Gold-Catalyzed C-H Functionalization Polycondensation for the Synthesis of Aromatic Polymers. Angew. Chem., Int. Ed. 2020, 59, 21971-21975.

(18) Reetz, M. T.; Sommer, K. Gold-Catalyzed Hydroarylation of Alkynes. Eur. J. Org. Chem. 2003, 2003, 3485-3496.

(19) Shi, Z.; He, C. Efficient Functionalization of Aromatic C-H Bonds Catalyzed by Gold(III) Under Mild and Solvent-Free Conditions. J. Org. Chem. 2004, 69, 3669-3671.

(20) Nakamura, A.; Ito, S.; Nozaki, K. Coordination-Insertion Copolymerization of Fundamental Polar Monomers. Chem. Rev. 2009, 109, 5215-44.

(21) Chen, J.; Gao, Y.; Marks, T. J. Early Transition Metal Catalysis for Olefin-Polar Monomer Copolymerization. Angew. Chem., Int. Ed. 2020, 59, 14726-14735.
(22) Guo, L.; Liu, W.; Chen, C. Late Transition Metal Catalyzed $\alpha$ Olefin Polymerization and Copolymerization With Polar Monomers. Mater. Chem. Front. 2017, 1, 2487-2494.

(23) Lu, Z.; Hammond, G. B.; Xu, B. Improving Homogeneous Cationic Gold Catalysis through a Mechanism-Based Approach. Acc. Chem. Res. 2019, 52, 1275-1288.

(24) Lau, V. M.; Pfalzgraff, W. C.; Markland, T. E.; Kanan, M. W. Electrostatic Control of Regioselectivity in $\mathrm{Au}(\mathrm{I})$-Catalyzed Hydroarylation. J. Am. Chem. Soc. 2017, 139, 4035-4041.

(25) Hashmi, A. S. K.; Blanco, M. C. Gold Catalysis: Observation of a Two-Fold Intermolecular Hydroarylation of Unactivated C-C Triple Bonds. Eur. J. Org. Chem. 2006, 2006, 4340-4342.

(26) Dorel, R.; Echavarren, A. M. Gold(I)-Catalyzed Activation of Alkynes for the Construction of Molecular Complexity. Chem. Rev. $2015,115,9028-72$.

(27) Ferrer, C.; Amijs, C. H.; Echavarren, A. M. Intra- and Intermolecular Reactions of Indoles with Alkynes Catalyzed by Gold. Chem. - Eur. J. 2007, 13, 1358-73.

(28) Jia, M. Q.; Bandini, M. Counterion Effects in Homogeneous Gold Catalysis. ACS Catal. 2015, 5, 1638-1652.

(29) Lu, Z.; Han, J.; Okoromoba, O. E.; Shimizu, N.; Amii, H.; Tormena, C. F.; Hammond, G. B.; Xu, B. Predicting Counterion Effects Using a Gold Affinity Index and a Hydrogen Bonding Basicity Index. Org. Lett. 2017, 19, 5848-5851.

(30) Lopez, S.; Herrero-Gomez, E.; Perez-Galan, P.; NietoOberhuber, C.; Echavarren, A. M. Gold(I)-Catalyzed Intermolecular Cyclopropanation of Enynes With Alkenes: Trapping of Two Different Gold Carbenes. Angew. Chem., Int. Ed. 2006, 45, 6029-32.

(31) Clavier, H.; Nolan, S. P. Percent Buried Volume for Phosphine and N-Heterocyclic Carbene Ligands: Steric Properties in Organometallic Chemistry. Chem. Commun. 2010, 46, 841-61.

(32) Marion, N.; Nolan, S. P. N-Heterocyclic Carbenes in Gold Catalysis. Chem. Soc. Rev. 2008, 37, 1776-82.

(33) Tubaro, C.; Baron, M.; Biffis, A.; Basato, M. Alkyne Hydroarylation With Au N-Heterocyclic Carbene Catalysts. Beilstein J. Org. Chem. 2013, 9, 246-53.

(34) Boaen, N. K.; Hillmyer, M. A. Post-Polymerization Functionalization of Polyolefins. Chem. Soc. Rev. 2005, 34, 267-75.

(35) Owens, D. K.; Wendt, R. C. Estimation of the Surface Free Energy of Polymers. J. Appl. Polym. Sci. 1969, 13, 1741-1747.

(36) Chang, Y.; Lee, H. H.; Kim, S. H.; Jo, T. S.; Bae, C. Scope and Regioselectivity of Iridium-Catalyzed $\mathrm{C}-\mathrm{H}$ Borylation of Aromatic Main-Chain Polymers. Macromolecules 2013, 46, 1754-1764. 